\title{
Improvements of Pre-Service Counselor Skill in Building Therapeutic Alliance Using Peer Coaching Method
}

\author{
Esya Anesty Mashudi* \\ Early Childhood Education Department \\ Universitas Pendidikan Indonesia \\ Serang, Indonesia \\ esyaanesty@upi.edu* \\ Nandang Rusmana \\ Guidance and Counseling Department \\ Universitas Pendidikan Indonesia \\ Bandung, Indonesia \\ nandangrusmana@upi.edu
}

\author{
Ima Ni'mah Chudari \\ Primary Teacher Education Department \\ Universitas Pendidikan Indonesia \\ Serang, Indonesia \\ nimahchudari@upi.edu \\ Fatihaturosyidah \\ Early Childhood Education Department \\ Universitas Pendidikan Indonesia \\ Serang, Indonesia \\ fatihaturosyidah@upi.edu
}

\begin{abstract}
It is necessary for every counselor to be equipped with a comprehensive understanding of the therapeutic alliance and do the same with skills to foster and maintain the therapeutic alliance with the counselee during the counseling process. Hence, mastery of the therapeutic alliance building skill should be acquired by all of pre-service counselor. This study aims to describe how the improvements of the pre-service counselor in building therapeutic alliance by using the peer coaching method is. This study was conducted by using action research to 32 pre-service counselors in guidance and counseling department of Universitas Pendidikan Indonesia. The research data were collected by using rating scale and test instrument. The data collected then were analyzed by using the interactive models of data reduction, data display and data generalization. The result of this uncovers the mastery level of pre-service counselor skill in building therapeutic alliance is at a low-level category. This point becomes an empirical data base determiner for selection the actions focus in training program implementation using peer coaching methods to improve the skill of pre-service counselor in building therapeutic alliance. The implementation of the action consists of three cycles. Each cycle consists of four stages, namely planning, implementation, observation and reflection. After doing the three cycles, in conclusion, there is a rising level point of the pre-counselor skill mastery. This increasing proportion number were shifted from low to high level, cycle by cycle. Each aspect of the therapeutic alliance building has reached beyond succed indicators determined previously.
\end{abstract}

Keywords-counseling skill, ethnopedagogy, indigenous wisdom, therapeutic alliance

\section{INTRODUCTION}

Guidance and counseling teacher or school counselor is a profession that has the responsibility in developing academic, career, and personal-social development of all students in schools. This is called as a profession because like other professions, the counseling field also emerge many professional characteristics requirements. According to the
Indonesian Counselors Competency Standards, implementation of guidance and counseling job must be occupied by a person who has basic knowledge and skills that are based on an expertise [1]

In the process of counseling, a counselor is an agent who gives enlightens to the counselee. Therefore, to sustain the role of a counselor, he or she should has the ability and skills to transform the counselee's behavior. Thus, counseling skills are considered as a very important person for students in supporting the success of the counseling process. A good counseling skills counselor has will lead to an effective counseling process.

One of the important counseling skills mastered by a counselor is the skill of building positive relationships that are full of trust, commitment in providing assistance, and agreement to achieve counseling goals together with counselees or better known as therapeutic alliances. The therapeutic alliances are oftenly also called as helping alliances, work alliances, ego alliances, pre-attending or therapeutic relationships [2].

The skills of fostering a therapeutic alliance is a substantial skill in counseling process that can bring the succeed of counseling process. Various counseling techniques require the counselor to firstly establish a therapeutic alliance with the counselee before using the technique. Therefore, the skill to foster this therapeutic alliance is one of the basic skills that pre-counselors need to master. This is in line with the opinion of Lambert and Barley research over the years [3] which give conclusion that the relationship factor between counselor and counselee correlates more strongly with the results achieved by the counselee at the end of the counseling process compared to the factors of special counseling techniques used by counselors in the counseling process.

The concept of a therapeutic alliance stems from studies of the therapeutic relationship. Alliances represent certain 
work elements of the relationship between counselor and counselee [4]. According to Gelso and Carter [5], relationships in counseling involves three main parts, namely: (1) transference and counter-transference, which refers to a person's reaction to another person based on significant relationships with certain people and unresolved psychodynamic conflicts; (2) alliance; and (3) the actual relationship, that is, the affective bond between the counselor and counselee regardless of the working relationship between the two.

Therapeutic alliances are divided into three components namely bonds, goals or goals and tasks $[6,7]$. From the consideration of these components, it can be seen that the therapeutic alliance is a relationship that emphasizes a collaborative partnership between counselor and counselee. The partner includes the counselee's goals and preferences related to the counseling process and methods for achieving that goal. Therapeutic alliances are mainly formed by the ability to 'listen' counselees without prejudice and without giving advice that is not responsible to counselee problems [8].

Rogers [9] suggested that therapeutic alliances should be emerged when counselors provide conditions that are 'needed' and 'adequate' for the counselee. These conditions must have sincerity, empathy, and unconditional acceptance directed at achieving therapeutic changes in personality.

It is important for prospective counselors to be equipped with a comprehensive understanding of the construct of the therapeutic alliance and the skills of fostering and maintaining a therapeutic alliance with the counselee throughout the counseling process. Various literature discusses how to establish a therapeutic relationship with counselee as in the theory that was coined by Rogers, Carkhuff, Ivey, Cavanagh, Bordin, and others. So that in terms of theory will not be left behind. However, as long as learning is limited to theory it will lead to a rigid and less flexible implementation especially when it clashes with cultural values and other practical elements.

Therefore, it is important to combine various theories about building therapeutic alliances with appropriate practice methods so that these skills can be mastered well by prospective counselors. One method that is considered representative is the peer coaching method. The peer coaching method was chosen because it is one of the methods widely used in education and training that is oriented towards best practices.

Peer coaches are selected from qualified experienced counselors, so they can share their experiences and suggestions regarding the implementation of counseling practices in the actual context. Prospective counselors in this case can gain deeper insights by having a peer coach, allowing them to apply new strategies learned from training sessions and get feedback on how the strategies are implemented in the actual counseling process.

Peer coaching can help professional practitioners to internalize what they have learned, how to apply it in their work, and take part in professional discussions about what they have learned. This form of follow-up will guarantee the transfer of learning, and help professional practitioners share ideas and strategies with one another [10].
Thus this study is focused on answering questions about "how to improve the skills of fostering therapeutic alliance of prospective counselors through the method of peer coaching?". To answer this question, an action research study was conducted aimed at examining the application of peer coaching methods to improve the skills of fostering therapeutic alliances for prospective counselors.

\section{METHODS}

\section{Design}

This study used Action Research approach. Action research in education is a form of applied research whose main purpose is to improve the practice of professional education itself [11]. Research is sometimes referred to as practitioner research, teacher research, insider research and (usually when done by teachers/ educators in their own practice) self-study research. Action research may use many research methods and involve collaboration with colleagues, clients, or professional researchers.

Glanz [11] analyzes the process of an action research project into six steps: (1) selecting focus; (2) take action (in the form of a cycle); (3) collecting data; (4) data analysis and interpretation; (5) reflection; and (6) continue or modify.

\section{Data Collecting Tools}

The instruments used in collecting data in this study are a rating scale of therapeutic alliance building skill and tests instruments to measure the knowledge of therapeutic alliance concepts. These instruments was developed based on the concept of a therapeutic alliance by Bordin [6] (1979; in Dryden \& Reeves, 2008). Other instruments used in this study are field notes instruments which is applied by peer coaches to observe and record important events during the training.

\section{Data Analysis}

Data analysis process was done during data collection process that takes place after completion of data collection in certain period. The type of data analysis used is qualitative data analysis from Miles and Huberman [12] (2002). Activities in the analysis of data consist of:

a) Data reduction, which summarizes, chooses the main points, focuses on the important things, looks for themes and patterns and discards unnecessary. Data reduction aims to provide a clearer picture and make it easier for researchers to perform further data collection.

b) Presentation of data, is the second step after data reduction. the presentation of data is done by organizing the data and arranging the relationship pattern. So it's easier to understand what's going on and to plan for further work.

c) Verification/ description of conclusions, namely drawing conclusions from the process of collecting data obtained from the field.

\section{RESULT AND DISCUSSION}

The initial description of pre-service counselors skill in building therapeutic alliance is obtained from the assessment results of the knowledge and skill 32 fourth year students (academic year 2018/2019) in the guidance and counseling department of Universitas Pendidikan Indonesia. 
The assessment focuses on the three components of therapeutic alliance namely bond, goal and task. All those components was assessed in two ways. Firstly, to measure students' knowledge of therapeutic alliance. Students have to fill the quiz about the concepts therapeutic alliance. Secondly, to assess student skill in building therapeutic alliance, a role play situation was being settled by the supervisor. There are a peer coach acting as the counselee which whom student has to face with. The way student build or foster therapeutic alliance between him/ her and the counselee, which also their peer coach was being assessed during the role play session to gain a data about pre-service skill in building therapeutic alliance.

The results of the assessment are presented in the form of proportion of respondents scores which indicate the level of mastery of skills in the low, medium and high level. Low level of skill mastery indicate novice category, medium level of skill mastery indicate average category, and high level of skill mastery indicate advance category. Table 1 depicts in detail the profile of pre-service counselors skill in building therapeutic alliance.

Table 1. Initial Description Of Pre-Service Counselor Therapeutic Alliance Building Skill

\begin{tabular}{|l|l|c|}
\hline \multirow{2}{*}{$\begin{array}{c}\text { SKILL MASTERY } \\
\text { LEVEL }\end{array}$} & \multicolumn{2}{|c|}{ Proportion } \\
\cline { 2 - 3 } & $\mathrm{N}$ & $\begin{array}{c}\text { in } \\
\text { percentage }\end{array}$ \\
\hline Novice & 15 & $46,88 \%$ \\
\hline Average & 13 & $40,62 \%$ \\
\hline Advance & 4 & $12,5 \%$ \\
\hline
\end{tabular}

Based on table 1, it can be seen that in general, out of 36 students, only $27.77 \%$ (10) students showed mastery of developing high-level therapeutic alliances. Meanwhile, as many as $30.55 \%$ (11 people) students showed mastery of skills to build a therapeutic alliance at a moderate level, and the remaining $41.66 \%$ showed mastery skills to foster a low level therapeutic alliance. The number of students with mastery of skills fostering low-level therapeutic alliances is the most dominant. Thus, it is clearly seen that there is a need for increased skills in developing a therapeutic alliance for fourth-year students in the guidance and counseling department which will be projected as counselors in the field.

The low level of mastery of skills refers to the novice category where the group of subjects shows characteristics related to the three components of skills to build a therapeutic alliance namely (1) the aspects of the counselor's bond have not displayed an empathic understanding of counselee issues, have not displayed sincerity and unconditional acceptance of the counselee, and have not able to modify his personal interpersonal style with the counselee's interpersonal style; (2) the goal counselor aspect has not been able to formulate the goals of the counseling process, has not been able to make an agreement with the counselee regarding the objectives to be achieved as well as an agreement to work together to achieve these goals, has not been able to conduct discussions and consolidation when there are differences in objectives between the counselor and counselee; (3) the aspects of the counselor's task have not been able to identify their tasks based on the counseling approach used, have not shown knowledge related to the technique to be performed and what of the technique, and do not share knowledge about the counseling technique used in the counselee.

The moderate or sufficient level of skill mastery refers to the average category where the group of subjects shows characteristics in the form of: (1) in the bond aspect counselor has been able to display an empathic understanding of counselee issues, able to display sincerity and unconditional acceptance of the counselee, but has not been able to modify the style personal interpersonal counselee interpersonal style; (2) in the goal aspect counselor has been able to formulate the goals of the counseling process, able to make agreements with counselees related to the goals to be achieved and an agreement to work together to achieve these goals, but have not been able to conduct discussions and consolidation when there are differences in objectives between counselor and counselee; (3) in the task aspect, counselor is able to identify his tasks based on the counseling approach used, have shown knowledge related to the technique to be performed and what of the technique, but have not shared the knowledge of the counseling technique used by the counselee.

The high level of mastery of skills refers to the advanced category which has the following characteristics: (1) the bond counselor aspect can display empathic understanding of counselee issues, can display unconditional sincerity and acceptance of the counselee, and be able to modify his personal interpersonal style with the counselee interpersonal style ; (2) the goal counselor is able to formulate the goals of the counseling process, able to make agreements with counselees related to the goals to be achieved and an agreement to work together to achieve these goals, and be able to conduct discussions and consolidation when there are differences in objectives between counselor and counselee; (3) the aspects of the counselor's task are able to identify his tasks based on the counseling approach used, can show knowledge related to the technique to be performed and what of the technique, and can share knowledge about the counseling technique used in the counselee so that the counselee obtains the required knowledge to do selfcounseling. Based on tracing at each level of mastery of skills building a therapeutic alliance can be obtained clearer information about which categories are most urgent to be trained and developed (focus selection). Based on a review of the field notes, as well as a focused discussion with the subject obtained feedback about the obstacles encountered by prospective counselors in fostering a therapeutic alliance with the counselee at the beginning of the counseling process, namely:

a. Counselors feel less confident in dealing with counselees, so there is often a fear of disappointing counselee who causes counselors to develop prejudice that the counselee does not like him and will not hear what he said.

b. Counselors only understand some of the techniques and approaches in counseling because many of them are taught at the beginning of the lecture and the counselor has forgotten about the material.

c. Counselors feel nervous when dealing with counselees because of lack of experience. 
d. The counselor is not yet aware of his interpersonal style so he cannot adjust the interpersonal style with the counselee.

With that in mind, a series of efforts to provide action through a skills training program fostering a more structured therapeutic alliance using peer coaching methods in which the peer coaches are field practitioners with a background in guidance and counseling knowledge and have experience as professional counselors for more than 2 years of service.

It is hoped that the involvement of these practitioners will be able to distribute more insights and knowledge to preservice counselors especially those needed to develop skills in developing a therapeutic alliance. The four stages in one action cycle become a series of training activities.

In the first cycle the most popular peer coach model is collegial coaching, where the peer coach and coachee are involved in collegial discussion. The coachee must start the conversation, and the peer coach as the observer adds factual information about what happened during the practice. Both can discuss things that are going well, and things that are not going well or not going at all. In addition, the discussion also focused on what needs to be changed or developed so that it has a positive impact on the running of practice.

To measure the effectiveness of the action, it is necessary to set an indicator of the success of the action, namely as much as $50 \%$ of the total subjects participating in the training show mastery of the skills of fostering therapeutic alliances at a high level or in the advanced category.

Based on the results of the assessment obtained elaboration that at the end of the 1st cycle the percentage of the number of subjects who showed mastery of skills fostering therapeutic alliances in the advanced category had not reached or exceeded $50 \%$ as specified in the indicators of the success of the action.

This shows that after going through the training process using the collegial coaching model there has not been a significant increase in mastery of skills in pre-service counselors.

Based on field notes, it is known in cycle 1 that the discussion is more focused on efforts to 'refresh' the subject's memory about theories around counseling techniques and approaches, such as behavioral, humanistic, gestalt, psychoanalysis, and so on. This is because many subjects forget and still lack understanding of the focus of the discussion.

Reflection on the implementation of cycle 1 implies several things that need to be improved and modified in cycle 2 . Thus, the problems that will be above in this cycle 2 in particular is how to create a deeper discussion, detailing each focus of the discussion carefully, and not just answer questions relating to personal difficulties that are subjective.

Therefore, after going through a process of discussion between the peer coach and the research team, then for the second cycle another peer coach model was chosen, namely the technical peer coach. Based on the assessment results obtained elaboration that at the end of cycle 2 the percentage of subjects with mastery of skills to develop therapeutic alliances in the advanced category has increased from cycle 1. However, even so the percentage has not reached or exceeded $50 \%$ as specified in the indicators of success of the action.

This shows that after going through training activities using the technical coaching model, it seems that there has been an increase in the mastery of skills to foster therapeutic alliances on subjects who become coachees even though the improvement has not been so significant.

Discussions that are more in depth, do not widen from the topics discussed, and focus more on the things that want to be improved are factors that support the increasing percentage of subjects who show mastery of skills to foster therapeutic alliances at a high level or that fall into the advanced category.

At the second meeting of cycle 3 , the team coaching model began to be applied. The team coaching model is a peer coaching that involves practitioners (as peer coaches) who are highly skilled and have good knowledge in specific work areas to work together with the trainees in order to develop certain skills or strategies related to the specific work area. In this model the two parties plan, implement and evaluate the success of professional practice. This means that:

a) Peer coaches and coaches must get interact with the target practice (counselee).

b) Peer coaches and coaches lead target practice groups (counselees).

c) Peer coaches and coaches give examples of target practice (counselee).

d) Peer coaches and coaches ask questions on target practice (counselee).

e) Peer coaches and coaches give instructions on the target practice (counselee)

Peer coaches and coaches are in the room where the activity or learning process takes place. The target practice will be aware of both of them in the room but not aware that one practitioner is more experienced and more insightful than other practitioners, and that the practitioner is there to support other practitioners in their efforts to learn, master, and acquire new skills related to professional practice.

Based on the results of the assessment of the subject's therapeutic alliance skills by the peer coach of each group, it was obtained that at the end of cycle 3 the percentage of subjects with mastering skills developing a therapeutic alliance at a high level experienced a significant increase from cycle 2, an increase also occurred in the other two categories

As previously expected, not only did stagnation not occur, the percentage of students with mastery of skills fostering therapeutic alliances at a high level had reached 50\%. This means that more than half of the subjects showed mastery of skills in the advanced category. Thus, it can be said that an indicator of the success of the actions in this study has been achieved.

Based on the recapitulation of the results of the skills assessment of counseling therapeutic alliances pre counselor can be seen an increase in mastery of skills to foster therapeutic alliances. This is indicated by an increase in the percentage of subjects who demonstrate mastery of developing therapeutic alliance skills at a high level or advanced category from cycle 1 to cycle 3 . 
Table 2. Final Description of Pre-Service Counselor Therapeutic Alliance Building Skill (After Third Cycle of Action)

\begin{tabular}{|l|c|c|}
\hline \multicolumn{1}{|c|}{$\begin{array}{c}\text { SKILL MASTERY } \\
\text { LEVEL }\end{array}$} & \multicolumn{2}{c|}{ Proportion } \\
\cline { 2 - 3 } & $\boldsymbol{N}$ & in percentage \\
\hline Novice & 0 & 0 \\
\hline Average & 15 & $46,88 \%$, \\
\hline Advance & 17 & $53,12 \%$ \\
\hline
\end{tabular}

In the novice category, the percentage decreased from $46,88 \%$ in cycle 1 , to 0 in cycle 3 . Meanwhile, in the average category, the percentage increased from $40,62 \%$ in cycle 1 , to $46,88 \%$ in cycle 3 Finally, in the advanced category, the percentage increased from $12,5 \%$ in cycle 1 , to $53,12 \%$ in cycle 3 . Thus, in general the actions taken in the form of training with the peer coach method imply a positive and effective impact on the skills of fostering therapeutic alliances.

The peer coaching method can help empower experienced practitioners in the field, so that collaboration between experts and practitioners can also be realized, this is certainly very beneficial because sharing expertise carried out by experts on practitioners can be a form of application in the scientific field in society.

In this study, the chosen peer coach is someone with a level of competence at the advanced level or those who have a deep and consistent understanding of carrying out the tasks according to specified standards, while pre-service counselors who are still students are someone with competency levels at the novice level or the most understanding level below when someone carries out tasks that he previously could not do [13]. The peer coach method allows practitioners who are skilled in specific work areas to share knowledge in order to develop new skills and abilities of other practitioners who have insights and knowledge at a lower level.

The strengths of the peer coach method have positive implications for improving skills in fostering a therapeutic alliance of pre-service counselors. The use of peer coaching methods in previous training also showed positive results in the development of certain skills. This is in line with the research of Becker [10] who found that peer coaching can bring a better understanding of best practices and curriculum. Peer coaching also contributes to the development of teaching and learning in schools. Teachers who participated in peer coaching training proved to be more skilled in carrying out the best practices of learning at South Virginia High School, this can be seen from the increase in the average score of skills obtained through evaluative studies for 2 years.

\section{CONCLUSION}

Based on a review of the research findings, the conclusions can be drawn as follows:

1. From the initial description, the number of students of the guidance and counseling department in the fourth year with the mastery of skills fostering a therapeutic alliance at a low level (novice) is dominant. As such, it is clearly seen that there is a need to improve their skills in developing therapeutic alliances for prospective counselors.

2. In implementing the action, a peer coaching method is implemented with three main models namely Collegial Coaching, Technical Coaching and Team Coaching in the form of training to improve skills to develop therapeutic alliance of prospective counselors.

3. Based on the final results of the skills assessment to foster therapeutic alliance pre-counselors, there is a finding that students' mastery of skills to foster therapeutic alliances is increase. This is indicated by an increase in the percentage of subjects with a mastery level in developing therapeutic alliances for pre-counselors at a high level (advance) from cycle 1 to cycle 3 . Increasing the number of subjects mastering the skills of developing a therapeutic alliance shows that in general actions taken in the form of training programs the peer coach method implies a positive and effective implications.

\section{REFERENCES}

[1] E.A. Mashudi and I.N. Chudari. Improving practical pedagogy competeny of kindergarten teacher candidates through peer coaching methods. [Proceedings of the $1^{\text {st }}$ international conference on education (ICE), Tasikmalaya, Indonesia, p. 21-32, 2017].

[2] Bedi, R.P., Davis, M. D., and Arvay, M.J., "The Client's Perspective on Forming a Counselling Alliance and Implications for Research on Counsellor Training," Canadian Journal of Counselling Vol.39 : p.2, 2005.

[3] Lambert, M. J., and Barley, D. E., "Research summary on the therapeutic relationship and psychotherapy outcome," Psychotherapy: Theory, Research, Practice, Training, 38(4), 357-361, 2001.

[4] Horvath, A. O., and Bedi, R. P., "The alliance. In J. C. Norcross (Ed.)," Psychotherapy relationships that work: Therapist contributions and responsiveness to patients (pp. 37-69. New York, NY, US: Oxford University Press, 2002.

[5] Gelso, C. J., and Carter, J. A., "The relationship in counseling and psychotherapy: Components, consequences, and theoretical antecedents". The Counseling Psychologist, 13(2), 155-243, 1985.

[6] Bordin, E.S., "The generalizability of the psychoanalytic concept of the working alliance," Journal of Psychotherapy: Theory, Research and Practice, 16(3): 252-60, 1979.

[7] Dryden, W., and Reeves, A. The handbook of individual therapy: sixth edition. London: Sage publishing, 2013.

[8] Daddario, A., and Kishimoto, E. Therapeutic Alliance Activity Quiz: Modul. COSIG Mobile Team: Australia, 2011.

[9] Green, S.J., Littell, J.H., Hammerstrom, K., Tanner-Smith, E., and Wilen, J.S., The Therapeutic Alliance and Psychotherapy Outcomes for Young Adults Aged 18 - 34: Protocol for a Systemic Review. USA: The Campbell Colaboration, 2012.

[10] Becker, J. M., "TNLI: Action research: Professional development: Peer coaching for improvement of teaching and learning". Research in teachersnetwork.org, 2000.

[11] Creswell, J.W. Educational Research: Planning, Conducting and Evaluating Quantitative and Qualitative Research (fourth edition). New Jersey: Pearson Prentice Hall, 2012.

[12] Miles, M.B., and Huberman, M. The qualitative researcher's companion. London: Sage Publishing, 2002.

[13] Shellabear, S. Competency Profilling: Definition and Implementation. ConsultSeven.com case, 2010. 